\title{
"A Tale of Two Hospitals": The Role of Place-Based Sensemaking in COVID-19 Communication for Rural and Urban Texas Hospitals
}

\author{
Cassandra Hayes $^{1}$ (D), Rachel E. Riggs ${ }^{1}$ (D) and Kelly Burns ${ }^{1}$ (i) \\ 1. College of Media and Communication, Texas Tech University, Lubbock, TX, USA
}

\begin{abstract}
Rural and urban hospitals must respond differently to crises such as the COVID-19 pandemic, given their unique situations. In this study, we performed a rhetorical analysis of press releases from rural and urban hospitals in Texas to better understand the crisis communication strategies of the two hospital systems. Following previous literature on narrative sensemaking, place-based storytelling, and pre-crisis management, we found that the examined press releases used setting details to ground their health-related information in their specific communities. Such a strategy made the information accessible and attainable, but potentially reinforced place-based tensions and inequalities. Our study has implications for preventative sensemaking research as well as for crisis communicators attempting to better reach specific communities during a long-term, developing crisis.
\end{abstract}

KEYWORDS: sensemaking, narratives, COVID-19, crisis communication, health communication

\section{ACKNOWLEDGMENT}

We would like to thank Dr. Bolanle Olaniran for early feedback that helped in developing this paper.

When rumors of a new, highly contagious virus began to circulate in early 2020, hospital administrators across the United

CONTACT Cassandra Hayes (D) - E-mail: cassandra.hayes@ttu.edu • College of Media and Communication • Texas Tech University • Box 43082 - Lubbock, Texas 79409, USA 
States began to revisit their crisis plans for handling a pandemic. The experiences of hospitals as they prepared for COVID-19 were not uniform; these hospitals and the communities they serve have well-established narratives that incorporate their unique situations, tensions, and ideals into their pre-crisis planning and crisis communication. For example, because of a lack of testing infrastructure in rural areas, confirmed case numbers may not be accurate in these areas (Weinberg, 2020). Also, larger hospitals in urban areas can see large influxes of patients, and these hospitals must treat their patients while using resources wisely and keeping workers safe (Chowdhury et al., 2020). In this study, we examined how the different challenges of rural and urban hospitals led to different approaches to COVID-19 crisis communication efforts that were particularly suited to each hospital's unique environment.

Crisis communication researchers, healthcare practitioners, and hospital administrators must better understand the ways in which rural and urban hospitals shape narratives to make sense of the pandemic and communicate with their stakeholders. Individuals perceive reality through narratives and often communicate their perceptions to others through stories (Fisher, 1984). Narrative sensemaking, as explored by Weick (1995) and Brown (2004), provides a useful theoretical foundation to investigate the methods used by rural and urban hospitals to plan for the COVID19 pandemic. Previous work on the need for anticipatory crisis management in order for an organization to respond effectively with crisis communication also has implications for our study, as we find that the cultivating of place-based exposition is essential to pre-crisis planning (Olaniran \& Williams, 2001). The storied past of hospitals and the communities in which they serve impacts every step of the pre-crisis planning stages and beginning stages of crises.

In this study, we examined online press releases using closetextual analysis in conjunction with contextual rhetorical criticism to compare the communication strategies implemented by two hospitals in Texas at the pre-crisis and early months of the COVID-19 pandemic in the United States. The two hospitals selected for this study include the Comanche County Medical Center (CCMC), a regional hospital serving rural communities in Comanche and 
Erath county, and the Methodist Health System (MHS), a large hospital system serving the Dallas-Fort Worth metropolitan area. In this study, we examine the use of place-based narratives as sensemaking tools, used in press releases of a rural and urban hospital as they attempted to manage the then-developing spread of the COVID-19 crisis. We argue that effective, preemptive placebased narrative exposition within crisis communication allows for better perceptions of legitimacy and relationship-building between an organization and its publics (Clementson, 2020; Lee \& Jahng, 2020; Yang et al., 2010). However, at the same time such narratives can also reinforce place-based tensions and inequalities that oversimplify or misrepresent multidimensional crises (Peterson, 2010). Through this comparative rhetorical analysis, we hope to better understand the unique place-based narrative sensemaking strategies used by rural and urban hospitals in preparation for the COVID-19 pandemic.

\section{Cases: Rural and Urban Hospitals Face COVID-19}

The impact of the COVID-19 global pandemic might be unprecedented, but researchers, practitioners, and doctors on the frontlines of healthcare in the United States were preparing for the crisis for months prior to its spread to the United States. Hospitals took several recommended steps to slow the outbreak and ease the pressure of treating COVID-19 patients (Centers for Disease Control and Prevention [CDC], 2020; Marx et al., 2020). Hospital preparedness can include strategies for using resources effectively and securing necessary funding, promoting organizational legitimacy, and fostering a trusting relationship with the public through pre-crisis communication. Despite early efforts to prepare for crises (CDC, 2018), hospitals in the United States were ill-prepared for such a long-term and wide-reaching crisis as COVID-19 (Cagliuso et al., 2008). The continued improvement of crisis communication strategies can help hospitals and other community leaders better prepare to reach out to their communities during future crises.

Previous literature in the fields of crisis communication and management has explored the importance of local context on crisis 
response. The situational crisis communication theory (SCCT) outlined the importance of context for how members of the public respond to crises, arguing that organizations should respond to crises based on how responsible they were for the crisis and how much their reputation hinges on their response (Coombs, 2007). Given such a theoretical foundation, the response of hospitals to a public health crisis is highly important to their legitimacy and reputation as organizations and impacts how they will respond to crises in the future. Further, construal level theory notes the importance of psychological distance on how the public responds to crises, as a person will not worry as much about an event perceived as far away as they will an event perceived as nearby or imminent (Liberman \& Trope, 1998; Spence et al., 2012). The foundational assumptions of crisis communication-that context matters-provides a helpful framework for understanding the different challenges shaping public perceptions in the early months of the pandemic, due to the differences in perceived distance between their communities and the crisis.

Rural and urban hospitals respond differently to crisis because of unique struggles, communities, and resources. During a crisis, rural hospitals like the CCMC must consume limited resources quickly. The planning and preparation process of an emergency situation is essential to rural hospitals because of limited access to equipment, supplies, personnel, and infrastructure (Office of Rural Health Policy, 2002). In the event of a long-term crisis such as COVID-19, rural hospitals have been brought to the brink of bankruptcy because of the quick depletion of resources without financial payouts. Even before the global pandemic, since 2010, 120 rural hospitals have had to shut down due to lack of funds, and over $21 \%$ of rural hospitals were found to be financially unstable (Topchik et al., 2020). Texas hospitals have not been immune from the issues facing rural hospitals. Many Texas hospitals were already struggling to stay financially afloat, and the COVID-19 pandemic did little to ease the pressure on limited staffing and resources (Walters, 2020). Texas rural hospitals' lack of personnel, funding, and resources created an urgent need for assistance in the response to COVID-19. 
Urban hospitals, such as the hospitals that comprise the MHS, faced their own unique challenges in response to COVID-19. Because of their multifaceted public as well as their larger internal membership and structure, urban hospitals must be transparent, correct rampant misinformation, and establish partnerships with diverse local communities in order to be effective with their crisis communication (Liu et al., 2018). Despite similar funding being set aside for disaster preparedness, rural and urban hospitals differ significantly in their available resources, crisis training, plan development, perceptions of preparedness, and surge capacityespecially essential during a pandemic (Vick 2019). Diffusing health information also faces different challenges in rural and urban areas. For instance, $25 \%$ of rural Americans do not have regular access to broadband internet, compared to less than $2 \%$ of urban Americans; $47 \%$ of rural hospitals are losing money with their operations; and $25 \%$ of rural hospitals are at a high risk of closing-leading to the hospitals having to limit some of their operations, such as public relations personnel and initiatives (Dornauer \& Bryce, 2020). Within the hospitals included in our analysis, the personnel difference in communications is striking-MHS has four individuals dedicated as media contacts and a full marketing department, while CCMC has only two on-staff individuals working on community outreach. In short, rural hospital emergency response requires a different response than urban hospitals due to differences in funding, location, and personnel.

\section{Literature Review}

\section{Narratives, Place, and Pre-Crisis Management}

Throughout history, people have used stories to make sense of the world around them, giving order to chaotic reality, navigating complicated life events and social systems through narrative structure (Fisher, 1984; Fisher, 1985). Narrative sensemaking theory examines such use of storytelling, attempting to explain how and why people use stories to make sense of social structures, relationships, crises, and other notable environments and events. Our analysis of press releases from CCMC and MHS during the COVID-19 crisis operates within the framework of narrative sensemaking 
theory, attempting to shed light on how rural and urban hospitals set up narrative structures within their rhetoric to build a trusting relationship, founded on legitimacy, with the members of their communities-a relationship that can withstand the tests of a crisis situation.

Crisis communication is a complex phenomenon central to the ability of organizations to survive and sustain themselves through uncertainty. Crisis response calls for three main goals: (a) disseminating instructing information, (b) disseminating adjusting information, and (c) reputation management (Coombs, 2015). One way organizations can simplify complex happenings to provide needs for action and avenues to act that lead to reaching crisis response goals and broader organizational goals is through establishing stories about environments and events. Brown (2004), expanding on Weick (1995), included narratives as an effective sensemaking strategy for organizations, as stories use hindsight to structure events for both individuals and a community. Sensemaking can be defined as the process of trying to explain and give meaning to a confusing or complex object or event in a more simplified and approachable manner, literally "making of the sense" (Weick, 1995, p. 4). Because narratives are so central to the human experience, they are especially apt in making sense of crisis events.

Prior scholarship on sensemaking focuses on the individual process of retrospectively sorting through crises. Sensemaking as originally outlined by Weick (1995) involves retrospection, a process of individuals looking back and sorting out past experiences. However, scholars such as Sandberg and Tsoukas (2015) have pointed out the need to examine prospective sensemaking that allows room for organizational change and can be more actively guided to shape future action. Within this study, we use the term preventative sensemaking, which we define as making sense of future action through communicating, interacting, and storytelling about a past action, to take a prescriptive approach. Under our conceptualization, preventative sensemaking involves recursive storytelling, recycling narratives to give meaning to future or developing events. These narratives do not spring from nowhere; they are inherently social and contextualized by nature. As explained by Weick (1995) sensemaking is always a social activity, 
as it involves an ongoing process of sorting through experiences and giving them meaning through a collective process of interaction within a social context. For this study, we focus not on how individuals recursively sort through crises through sensemaking, but, rather, on how organizations can guide a preventative sensemaking process for their members and the public through effective storytelling.

Narrative sensemaking scholars have generally identified narratives according to three criteria: (a) involvement of characters, (b) action ordered to create causal inferences, and (c) a setting that constrains the action (Abolafia, 2010; Boje et al., 2016; Boudes \& Laroche, 2009). Within this study, we focus particular attention on settings and social contexts, including place-based details and invocations of place, that guide the preventative sensemaking process.

\section{Place-Based Storytelling}

Organizational stories are not one-size-fits-all constructionsthey reflect and respond to the community that surrounds and circulates them. Tisch and Galbreath (2018) noted a phenomenon they called "community sensegiving," in which an organization's social connection to the surrounding public plays a large role in organizational resiliency and the ability to survive through crisis. Recently, scholars such as Clementson (2020) and Lee and Jahng (2020) have noted the importance of narratives in crisis communication, as stories are powerful persuasive tactics, can shift blame and act as vehicles for essential information, and can build legitimacy and trust for an organization. Further, organizational communication, including crisis communication, cannot be separated from its surrounding context, as risk itself is socially produced and shaped by the culture that surrounds it (Masuda \& Garvin, 2006). As Peterson (2010) found, in order to be effective, crisis and health communicators must consider the place-based nature of the information and assurance they are trying to communicate. Long before a crisis event occurs, public relations practitioners should be carefully shaping sensemaking stories that reflect a deep knowledge of the specific community that surrounds the organization. 
Crisis sensemaking narratives involve rhetoric that fits the situational context and a shared sense of meaning perceived by the public and members of an organization (Gephart, 2007). Although not much work has examined the important dimension of place in sensemaking narratives, scholars have found that consideration of context is essential to encouraging effective sensemaking (Ingle et al., 2011). Further, setting is often identified as a central ingredient of narratives that constrains the actions of characters and the progress of characters. Many rhetorical analyses of sensemaking narratives focus on characters and causal action, determining how blame can be shifted within a text, or the specific persuasion tactics of organizational communicators (Boje et al., 2016; Boudes \& Laroche, 2009). The important constraints and impact of setting, especially placed-based exposition or backstory, is an underexplored topic in rhetorical crisis communication studies on sensemaking, but one that needs much further research, given the importance of context to crisis communication as well as the need for crisis communicators to reach specific communities with information.

Place-based storytelling includes narratives that invoke specific dimensions and qualities of the setting where the characters live and action happens. Rather than a macro-narrative that offers an omnipresent, god-like view of the larger forces behind a story, placed-based storytelling is micro-focused, explaining small dayto-day details of life in that specific place. At times, place-based stories are essential to fully explaining a larger narrative, as Moors (2019) noted with the Flint water crisis, because public media stories do not always capture the full experience of everyday citizens. Further, place-specific details can act as unifying rallying points to build legitimacy for a movement or organization (Endres \& Senda-Cook, 2011). In crisis communication, a situation when making information accessible is key, close attention to constructing and reflecting setting through the use of place-based narratives can better reach multifaceted and dispersed communities.

We argue that invocations of place are central to preventative sensemaking storytelling. An extension of place-based storytelling, in which small details about the specific geographical context are used to describe the setting of narratives, invocations of 
place occur when rhetors, such as crisis communicators, recall past action and behavior of a place's community in order to guide future or developing action. The term invocations is often used in the context of ancient Greek rhetoric, such as the work of Homer, when ancient rhetors used invocations, calls to deities or spiritual forces, to boost their own credibility as speakers and offer a cue for the story pattern to follow (Minchin, 1995; Minton, 1960). Going beyond simple inclusion of setting, context, or place-based details, an invocation of place is a call to action or request for help from the forces of the place itself. It is recalling the recycled narratives of a place to be used to make sense of future or developing action, and is, therefore, a central feature of preventative sensemaking.

\section{Exposition and Crisis Preparedness}

We focus our rhetorical analysis for this study on press releases during the early months of the COVID-19 crisis in the United States before a surge of COVID-19 patients began reaching either CCMC or the MHS. Our focus is on pre-crisis communication and management, specifically the narratives that the press releases presented to the public in an effort to guide the hospitals' communities through a sensemaking process for the imminent pandemic. To inform our interpretations of the impacts of the pre-crisis narratives, we use the Anticipatory Model for Crisis Management as outlined by Olaniran and Williams (2001). Particularly, we accept the idea that crisis management begins long before an actual crisis occurs, and effective crisis communication hinges on the many steps taken to manage a crisis preemptively and ethically.

Narrative sensemaking as a process relies on hindsight using story structures to sort out confusing events or complex circumstances that have been confronted in the past (Boudes \& Laroche, 2009; Brown, 2004; Bute \& Jensen, 2011). However, the press releases we analyzed show that organizations can offer placedbased expository narratives and invocations of place that encourage members of the public to use similar stories to make sense of crisis events that may occur in the future. In other words, crisis communicators can offer pre-planned structures to guide the public's sensemaking process, as long as the narratives used are specific to the public's setting and meet each community's individual 
needs. Previous studies show that narratives are not a handy sensemaking technique that springs from nowhere following a crisis. Rather, narratives need to be cultivated around and within organizations in order to be used in crisis situations to maintain the legitimacy and stability of an organization (Auvinen et al., 2013; Golant \& Sillince, 2007; Patriotta, 2003). Such past research implies the possibility of crisis communicators fostering anticipatory narrative sensemaking strategies.

Practitioners of organizational communication should keep in mind that they are perpetually building potential exposition for future narratives that will be used to make sense of crises and the organization itself. Exposition is backstory, a pause in the action of a narrative during which the narrator explains past events. Exposition frames a narrative, giving it both context and meaning, and, as found by Alexander (1997), exposition guides the motivations and knowledge-seeking of the audience. The previous goals of crisis response all require effective, but different, application of expository details within communications. Instructing information, by nature, must communicate specifics about place in order for the public to understand what to do to protect themselves during a crisis, while reputation management can include reminding the public of the organization's positive past action in the community (Coombs, 2015). Such an understanding of the goals of crisis response emphasizes that, to sustain themselves, organizations must have a positive backstory of some kind that can be reinforced during a crisis. Using the concepts of setting and exposition, our analysis of CCMC and MHS press releases during the early COVID-19 crisis emphasizes that pre-crisis placed-based activities set up the success or failure of the public's eventual narrative sensemaking strategies. The research questions guiding our analysis include:

RQ1: How are (a) invocations and (b) characterizations of place used in the press releases of CCMC and MHS during the early months of the COVID-19 crisis in the United States?

RQ2: What is the rhetorical impact of characterizations of place in the press releases of CCMC and MHS during the early months of the COVID-19 crisis in the United States? 


\section{Method}

For this study we conducted a rhetorical analysis, specifically a close-textual analysis that examined particular persuasive and narrative features of each included artifact. Although we look at the text of each press release in isolation to determine rhetorical features at work within the text, we also consider the larger social and organizational context of each crisis communication artifact, guided by our research questions. The analysis was comparative in nature-six press releases from CCMC were analyzed in isolation, then four press releases from the MHS were analyzed. The press releases under analysis were chosen as the only press releases on the organizations' websites, directly before and within the early months of the COVID-19 crisis in the United States, published between January 2020 and early June 2020. Following the close-textual analysis of the press releases themselves, we then studied the larger social context for how CCMC and the MHS faced the COVID-19 pandemic. In the tradition of other rhetorical analyses, such as Carpenter (1977) and others (Crines, 2013; Hamlet, 2011), we conceptualize "rhetorical impact" as highly interpretive, determined through examination of the texts themselves and their surrounding historical and cultural context.

Because around eight in ten questions about health start through seeking information online (Fox \& Duggan, 2013), we chose to analyze only press releases readily available on hospital websites. Although many sensemaking studies examine how individuals both within organizations and in the public retrospectively sort through crisis situations, we instead focus on how the CCMC and MHS attempted to guide their communities through a preventative sensemaking process. Therefore, we are focused more on the organizational statements themselves, rather than public perception of how the organizations handled the crisis. Press releases are by their nature meant to guide the narrative surrounding organizational events, both when published online by the organization or sent directly to journalists, and press releases serve as a foundation on which members of the media can build a larger story (Lassen, 2006). As we are attempting to analyze the preventative sensemaking process and how an organization can guide the 
narratives that individuals may later use to make sense of an event, press releases are appropriate artifacts for analysis.

Although we include case study contextual information in our analysis, the bulk of our analysis takes a rhetorical approach. A rhetorical approach to studying crisis communication examines the development, framing, and interpretation of messages created by organizations, as pre-crisis threats and crises task organizations to create messages that demonstrate the organization's wisdom and position the organization as ethical in a strategic way (Heath \& Millar, 2003). In this analysis of the pre-crisis management of CCMC and MHS, we view press releases released during the pre-crisis planning phase as "rhetorical statements designed to demonstrate the commitment, trustworthiness, and alignment of a company with community interests" (Heath \& Millar, 2003, p. 7). Given the limited number of press releases analyzed by this study, we attempt not to make broad claims about the effects of the pre-crisis communication of these organizations-rather, the limited amount of artifacts allows us to analyze deeply the narrative sensemaking strategies within the text, aligning with our study's exploratory aim to better understand how place-based narratives can be used in pre-crisis communication to guide the sensemaking process for the public when a crisis does occur.

\section{Analysis}

Place-based indicators act as the setting dimension of the narratives that press releases tell and are essential in guiding members of the public toward sensemaking strategies that allow the community to both accept a crisis and respond well to a crisismanaging organization. Scholars have studied the textual dimensions of press releases as a genre, outlining their common format as well as the importance of their context to understanding their structure (Catenaccio, 2008; Lassen, 2006). Despite the importance of contextual considerations with press releases, scholars and crisis communicators have overlooked the importance of place-based signals within effective press releases.

To answer RQ1, we argue that in the press releases we analyzed, invocations of place and characterizations of place, or setting 
details, were used in a similar fashion as with social movements, to build legitimacy and community (Endres \& Senda-Cook, 2011). Although press releases are often used as vehicles to get organizational and/or emergency information to the media and, ultimately, the public (Lassen, 2006), we find that in the CCMC and MHS press releases place-based information worked on several layers, advancing information but also building legitimacy for the organizations and providing a foundational frame to guide readers' sensemaking process. First, invocations of place ground the reader, reinforcing a sense that the crisis communicators were speaking directly to and from a community that they know well. Secondly, characterizations of place offer a space for narrative exposition, in which the crisis communicators could explain to readers all the pre-crisis steps taken in order to maintain stability and keep individuals safe. Even without concrete evidence of any kind, the use of setting fleshes out expository descriptions, making past actions seem justifiable and concrete. Third, place-based appeals within the rhetoric of the press releases we analyzed make the steps offered to manage the COVID-19 crisis feel attainable, as they are grounded in a specific location well-known to the hospitals' publics and placed in the accessible context of previous organizational actions.

\section{Invocations of Place}

RQ1a asked how invocations of place were used within the rhetoric of CCMC and MHS press releases. Invocations of place call directly to the culture and values of the community in its specific geographic location. The CCMC relied heavily on invocations of place, emphasizing the small-town community atmosphere of the CCMC public, situating COVID-19 in the context of local values such as neighbors helping out neighbors. The CCMC press releases contained several calls to action, specific lists and information to help "flatten the curve" in the spread of COVID-19 (CCMC, 202ob, para. 2). "Recipients are asked to follow volunteer directions during the event, wear a face covering or mask, remain in their car, leave windows up and have trunks open," one press release states in the context of a regularly held community 
food pantry (CCMC, 202od, para. 3). Another asks all residents of Comanche County to follow seven steps to contain the virus (CCMC, 202ob), and yet another outlines, "Calling ahead and notifying medical staff of recent travel and symptoms will help CCMC better accommodate patient care needs" (CCMC, 2020c, para. 1). The CCMC press releases outline specific actions that the community members themselves can take to help each other survive the crisis.

Such specific calls to action in crisis communication are not especially noteworthy, as emergency situations require the organizations involved to attempt to diffuse potentially lifesaving instructing information. However, the way such calls to action are contextualized within the rhetoric of the CCMC press releases sheds light on how CCMC attempted to guide a preventative sensemaking process with their narratives, using invocations of place. All calls to action, detailing specific action members of the public can take to slow the spread of the virus, are situated within stories about regular community initiatives that take place even in non-crisis periods. The food pantry in which social distancing protocols are outlined, the press releases remind readers, are "normally held on the CCMC campus," regular instances of volunteers from the community coming together to help the less fortunate (CCMC, 2020d, para. 1). Even the official statement included by Dr. L. G. Troxell, CCMC Chief Executive Officer, applauds healthcare staff for "answering the call to serve" the community during the crisis, realizing "CCMC's vision statement" (CCMC, 2020e, para. 5). Any calls to action to help guide behavior and perception during the COVID-19 crisis do not spring from nowhere-rather, they are grounded in the specific community CCMC serves, reflecting and reinforcing small-town neighborly values.

\section{Characterizations of Place}

RQ1b focused on how characterizations of place were used in CCMC and MHS press releases. Although still using place-specific details within their press releases, MHS differs in their rhetoric, focusing less on invocations of place and more on characterizations of place. CCMC calls on the community to come together to fight 
the COVID-19 crisis, emphasizing past community initiatives and noting the steps that residents can take to slow the spread of the virus. On the other hand, MHS instead emphasizes their own actions as an organization, using setting-specific details to show how they have cared for their community in the past, using placebased details to advance reputation management within their crisis rhetoric. For instance, one press release mentions education resources offered by the hospital system to one community (MHS, 2020a) while others detail the organization's work in South Dallas (MHS, 2020c; MHS 2020d). MHS provides "the only two hospitals and trauma centers south of downtown Dallas," according to one of the press releases (MHS, 2020d, para. 5). Such an emphasis builds rhetorical credibility in their press releases, establishing the organizational legitimacy so important for an organization hoping to sustain themselves through a crisis (Clementson, 2020; Gephart, 2007; Golant \& Sillince, 2007). The press releases characterize the MHS community through focusing on the agency and actions of the organization, MHS providing the scaffolding to the everyday functions of the geographic places the hospital system serves.

Despite differences in the context and use of place-based descriptions and appeals, both CCMC and MHS used settingspecific details to flesh out exposition in the stories they told about themselves as organizations and the COVID-19 crisis. Such expository place-based descriptions could be interpreted as adjusting information, setting readers' minds at ease by assuring them that the hospitals care for their communities. One press release boasts, "CCMC already had a best practice cleaning and maintenance system in place," which happened to also help contain COVID-19 (CCMC, 2020e, para. 4). An MHS press release describes an "ageold method" of treatment that "is new again" when describing their current use of the antiviral drug Remdesivir (MHS, 2020b, para. 11). An MHS press release also contextualizes current collaboration between North Texas hospitals to expand COVID-19 testing by noting past initiatives and collaborations to aid southern Dallas county (MHS, 2020c). Within the press releases during the early months of the COVID-19 pandemic, despite the unprecedented nature of the crisis, no actions taken were described as unprecedented-rather, organizational action was backed up with 
descriptions of past action specific to the organizations' communities. Such exposition reminds readers of past strategies and initiatives specific to their communities, thus cultivating the social meaning-making context through which individuals can interpret future events, such as the then-developing pandemic. In other words, use of expository setting details provides the foundation for a preventative sensemaking process, in which the organizations offered a narrative frame on which the public could build their interpretations, perceptions, and, ultimately, actions during developing future events.

\section{Place-Specific Impact}

The rhetorical impact of characterizations of place in the press releases of CCMC and MHS during the early months of the COVID-19 crisis in the United States varies according to each hospitals' situation and community. The different implications of the different narrative frames and contextualization of setting details is explained further in the Discussion section. However, rhetorically, for both CCMC and the MHS, place-based details bring credibility to the rhetoric of the crisis management press releases. Given the central role of discourse to building organizational legitimacy, and, in turn, the central role of discourse-built organizational legitimacy to institutional stability (Cornelissen et al., 2015), effective use of expository setting details to manage developing or forthcoming crises is essential to crisis communicators effectively navigating a crisis situation, especially in the long term.

Assumptions about the hospitals' communities appear in the rhetoric of the press releases, with large implications about who can and should access the crisis management information. One CCMC release, touching on ways to access health information through technology, clarifies that the "applications ... downloaded on a patient's computer or mobile device" can also be called "apps," signaling that not every reader of the release will be thoroughly familiar with digital technology (CCMC, 2020e, para. 2). Such a clarification displays effective knowledge of CCMC's rural community, especially given the digital divide and limited access to broadband internet in many rural areas across the United States 
(Dornauer \& Bryce, 2020). In contrast, the MHS assumes access to digital technology and the internet, stating at the end of their May 7 release: "Those who have recovered from COVID-19 are encouraged to consider donating plasma. Visit Carter Blood Care to request eligibility" (MHS, 2020b, para. 16). Although both CCMC and MHS press releases point to specifics of setting to contextualize the developing crisis, those specifics are placed in very different narrative frames with very different assumptions about which members of the public are consuming the crisis-related information.

\section{Discussion}

The MHS faces the challenge of serving a very diverse community with varying cultural norms, beliefs about healthcare, and ability to access digital resources. There are notable differences between the community CCMC serves and the community MHS serves, including differences in education level and racial demographics. The Dallas/Fort Worth area has a higher percentage of high school graduates and individuals with at least a bachelor's degree than Comanche and Erath counties served by CCMC (U.S. Census Bureau, 2018a \& 2018b). Such a holistic higher education level might explain the tone of the MHS's press releases, which speak in clinical language to an assumed audience that is internetconnected and able to seek out resources on their own. The holistic higher education level might also explain why most community initiatives, when they are specified in the releases, focus on education projects.

However, despite the higher education level of the DFW area as compared to Comanche and Erath counties, in which 95.6\% of persons identify racially as White alone, around $20 \%$ of DFW individuals identify as Black, around $40 \%$ as Hispanic or Latino, and only around $63 \%$ as White alone (U.S. Census Bureau, 2018a \& 2018b). Given that Pew Research Center identified Black and Hispanic individuals as more likely to distrust the medical profession and see medical misconduct as an important problem (Funk et al., 2019), that the MHS speaks within their press releases in such 
a clinical tone with non-transparency in deliberation and action, brings attention to the identity of their assumed audience, and weight to the possible implications that such rhetoric-especially in the context of a crisis-further alienates individuals in their community. Such implications are further tragic when faced with the increasing rates at which COVID-19 deaths and cases are disproportionately impacting Black, Hispanic, and Latino individuals (Godoy \& Wood, 2020). Left out of the narratives included in the MHS press releases directly prior to and during the initial stages of the COVID-19 outbreak, communities of vulnerable population groups are left unable to get the resources they direly need.

\section{Implications}

The findings of this research can be used by researchers, crisis communication practitioners, and hospital administrators to inform the use of press releases for shaping ideas about place through narrative sensemaking. Practitioners and hospital administrators working in rural and urban hospitals can use this research to bolster their efforts to not only reach out to the communities they serve with timely, helpful information, but to help the communities and themselves create and shape a narrative about how the organization and community will manage the crisis together. Press releases and external communication that intentionally frame information to best appeal to the communities to which they serve might help hospitals maintain strong relationships with their communities as COVID-19 continues to impact daily life. More research is needed to better understand the impact of crisis communication messaging on the community's perceptions of the organization within the context of COVID-19 and other epidemic and endemic viruses and diseases (Kim et al., 2009; Malecki et al., 2020).

Our study has implications for previous work on narrative sensemaking. Specifically, we offer an argument for preventative sensemaking-while much sensemaking research examines how individuals use narratives to sort out past events, our study examines how organizations can offer sensemaking narratives to guide perceptions of developing crises. Given the long-term, complex nature of the COVID-19 crisis, such preventative sensemaking 
could have huge implications for crisis communicators attempting to guide the perceptions of the public during crises without easily or quickly attainable conclusions or solutions. Our study also begins to shed light on not only the exotextual process of sensemaking, but the textual dimension-focusing not just on how people perceive crises, but the textual and rhetorical elements of content that can shape individuals' perceptions.

Assumptions presented by narrative frames, especially when those narrative frames are presented in order to help the community make sense of a crisis, can lend rhetorical credibility to crisis communication initiatives. However, such use of setting-specific stories can also trigger place-based tensions and inequalities, limiting who gets access to sensemaking narratives as well as crucial health-related information. Scholars of crisis response narratives such as Heath (2003) and Clementson (2020) have noted the centrality of stories to shaping organizational legitimacy and trust following a crisis. Crisis communicators must also consider how the use of setting-specific narratives helps flesh out and make more effective crisis communication while considering how such place-based details can also oversimplify a larger crisis into a tale reinforcing community tensions (Peterson, 2010). Part of such consideration involves the continued pre-crisis development of community relationships that can be used as place-based exposition should a crisis occur. By bringing close analysis of literary elements such as exposition and setting to the study of sensemaking narratives, scholars and practitioners can better begin to understand the nuances in language that contribute to preventative sensemaking narratives about crises.

\section{Conclusion}

Organizations are constantly building the beginnings of sensemaking narratives that crisis communicators could later offer to the public. Key to such narratives is a deep knowledge of the place where the organizations are situated and where the members of their communities live. In this study, we found that place-based setting details are rhetorically powerful in press releases meant to 
help manage a developing long-term crisis. The press releases of CCMC and the MHS during the first few months of the COVID19 crisis in the United States display narrative strategies that the organizations offered their communities to make sense of the imminent crisis. Expository setting details in these sensemaking stories allowed for the communities to brace themselves for the crisis and grounded crisis management actions in the circumstances attainable and accessible for members of each hospitals' public. However, such narratives also place limiting place-based frames on the developing crisis, constraining how the crisis was ultimately managed by each community.

Despite the limitations of an exploratory rhetorical analysis such as this one, including a small sample size and a focus on only digital press releases, our study sheds light on a preventative sensemaking process, which is especially important for crisis communicators to foster relationships with the community as a long-term crisis is just beginning to develop, or before the crisis develops at all. A crucial element of preventative sensemaking involves the use of setting details to make essential information attainable and accessible to the particular public the organization serves. Our analysis suggests that such details do not need to be elaborate descriptions, but rather specific expository instances of the organization helping the community in the past or understanding the past nature of the community. Although these setting details are important rhetorically to build credibility for the organization, crisis communicators must carefully consider the details they choose, as narrative frames can guide and constrain the public's sensemaking process in ways that fall prey to already-existent community tensions and inequalities. Further research on setting details in crisis communications of other cases, how place-based details are used differently within instructing and adjusting information and reputation management, as well as longitudinal studies that consider real-world effects of such rhetoric, could further illuminate this topic.

The press releases used in this analysis did not extend past July 2020 as CCMC and MHS were in the crisis phase of managing COVID-19. As COVID-19 continues to spread through communities, more research is needed to understand the prolonged crisis 
response of hospital officials and practitioners. In addition, future research could longitudinally analyze the crisis response of hospitals as they eventually shift to a post-crisis response.

\section{ORCID}

Cassandra Hayes (10) https://orcid.org/oooo-0003-3028-7551 Rachel E. Riggs (1) https://orcid.org/0000-0003-3771-5010 Kelly Burns (1) https://orcid.org/o0oo-0003-3145-5254

\section{References}

Abolafia, M. Y. (2010). Narrative construction as sensemaking: How a central bank thinks. Organization Studies, 31, 349-367. https://doi.org/10.1177/0170840609357380

Alexander, P. (1997). Knowledge-seeking and self-schema: A case for the motivational dimensions of exposition. Educational Psychologist, 32, 83-94. https://doi.org/10.1207/ s15326985ep3202_3

Auvinen, T., Aaltio, I., \& Blomqvist, K. (2013). Constructing leadership by storytelling-The meaning of trust and narratives. Leadership \& Organization Development Journal, 34, 496-514. https://doi.org/10.1108/LODJ-10-2011-0102

Boje, D. M., Haley, U. C., \& Saylors, R. (2016). Antenarratives of organizational change: The microstoria of Burger King's storytelling in space, time and strategic context. Human Relations, 69, 391-418. https://doi.org/10.1177/0018726715585812

Boudes, T., \& Laroche, H. (2009). Taking off the heat: Narrative sensemaking in post-crisis inquiry reports. Organization Studies, 30, 377-396. https://doi.org/10.1177/017084060810 1141

Brown, A. D. (2004). Authoritative sensemaking in a public inquiry report. Organization Studies, 25, 95-112. https://doi. org/10.1177/0170840604038182

Bute, J. J., \& Jensen, R. E. (2011). Narrative sensemaking and time lapse: Interviews with low-income women about sex education. Communication Monographs, 78, 212-232. https://doi. org/10.1080/03637751.2011.564639 
Cagliuso, N. V., Lazar, E. J., Lazar, A. N., \& Berger, L. J. (2008). Hospital emergency preparedness. In J. Pinkowski (Ed.), Disaster Management Handbook (pp. 369-385). CRP Press. https://doi.org/10.1201/9781420058635

Carpenter, R. H. (1977). Frederick Jackson Turner and the rhetorical impact of the frontier thesis. Quarterly Journal of Speech, 63, 117-129. https://doi.org/10.1080/00335637709383373

Catenaccio, P. (2008). Press releases as a hybrid genre: Addressing the informative/promotional conundrum. Pragmatics, 18, 9-31. https://doi.org/10.1075/prag.18.1.02cat

Centers for Disease Control and Prevention. (2018, Jan. 23). Crisis \& emergency risk communication. https://web.archive.org/ web/20171208141234/https://emergency.cdc.gov/cerc/

Centers for Disease Control and Prevention. (2020, March 25). Coronavirus disease 2019 (COVID-19) hospital preparedness checklist. https://web.archive.org/web/20200707075524/ https://www.cdc.gov/coronavirus/2019-ncov/hcp/hcphospital-checklist.html

Chowdhury, J. M., Patel, M., Zheng, M., Abramian, O., \& Criner, G. J. (2020). Mobilization and preparation of a large urban academic center during the COVID-19 pandemic. Annals of the American Thoracic Society. (Advanced online publication.) https://doi.org/10.1513/AnnalsATS.202003-259PS

Clementson, D. E. (2020). Narrative persuasion, identification, attitudes, and trustworthiness in crisis communication. Public Relations Review, 46, 1-9. https://doi.org/10.1016/j. pubrev.2020.101889

Comanche County Medical Center. (2020a, January). 2020 blood drive a success. [Press Release]. https://web.archive.org/ web/20210412160853/https://www.comanchecmc.org/2020blood-drive-a-success/

Comanche County Medical Center. (2020b, March 12). Patient screening implemented at hospital to help prevent spread of COVID-19 call ahead. [Press Release]. https://web.archive. org/web/20210412160939/https://www.comanchecmc.org/ patient-screening-implemented-at-hospital/ 
Comanche County Medical Center. (2020c, March 16). All residents asked to follow emergency plan to reduce COVID-19 cases. [Press Release]. https://web.archive.org/ web/20210412161843/https://www.comanchecmc.org/allresidents-asked-to-follow-emergency-plan/

Comanche County Medical Center. (2020d, April 16). CCMC hosts April 23rd mobile food pantry with two area churches as provisional distribution sites. [Press Release]. https:// web.archive.org/web/20210412161007/https://www. comanchecmc.org/april-23rd-mobile-food-pantry/

ComancheCountyMedicalCenter.(2020e,April21).CCMCemploys best practices at health system sites. Infection control and safety protocols are working-Patient visits steady. [Press Release]. https://web.archive.org/web/20210412161048/https:// www.comanchecmc.org/ccmc-employs-best-practices-athealth-system-sites/

Coombs, W. T. (2007). Protecting organization reputations during a crisis: The development and application of situational crisis communication theory. Corporate Reputation Review, 10, 163176. https://doi.org/10.1057/palgrave.crr.1550049

Coombs, W. T. (2015). Ongoing crisis communication: Planning, managing, and responding. Sage.

Cornelissen, J. P., Durand, R., Fiss, P. C., Lammers, J. C., \& Vaara, E. (2015). Putting communication front and center in institutional theory and analysis. Academy of Management Review, 40, 10-27. http://dx.doi.org/10.5465/amr.2014.0381

Crines, A. S. (2013). An analysis of George Galloway's oratorical and rhetorical impact. Politics, 33, 81-90. https://doi. org/10.1111/1467-9256.12003

Dornauer, M. E., \& Bryce, R. (2020, October 28). Too many rural Americans are living in the digital dark. The problem demands a New Deal solution. Health Affairs. https://www.healthaffairs. org/do/10.1377/hblog20201026.515764/full/

Endres, D., \& Senda-Cook, S. (2011). Location matters: The rhetoric of place in protest. Quarterly Journal of Speech, 97, 257-282. https://doi.org/10.1080/00335630.2011.585167 
Fisher, W. R. (1984). Narration as human communication paradigm: The case of public moral argument. Communication Monographs, 51, 1-22. https://doi.org/10.1080/03637758409 390180

Fisher, W. R. (1985). The narrative paradigm: An elaboration. Communication Monographs, 52, 347-367. https://doi. org/10.1080/03637758509376117

Fox, S., \& Duggan, M. (2013, January 15). Health Online 2013. Pew Research Center. https://web.archive.org/web/ $20191106040757 /$ https://www.pewresearch.org/internet/ 2013/01/15/health-online-2013/

Funk, C., Hefferon, M., \& Johnson, C. (2019, August 2). Trust and mistrust in American's views of scientific experts. Pew Research Center. https://web.archive.org/web/20190802153708/https:// www.pewresearch.org/science/2019/08/o2/trust-andmistrust-in-americans-views-of-scientific-experts/

Gephart Jr., R. P. (2007). Crisis sensemaking and the public inquiry. In Pearson, C. M., Roux-Dufort, C., \& Clair, J. A. (Eds.) International handbook of organizational crisis management. Sage. http://dx.doi.org/10.4135/9781412982757

Godoy, M., \& Wood, D. (2020, May 30). What do coronavirus racial disparities look like state by state? NPR. https://web. archive.org/web/20200530104953/https://www.npr.org/ sections/health-shots/2020/05/30/865413079/what-docoronavirus-racial-disparities-look-like-state-by-state

Golant, B. D., \& Sillince, J. A. (2007). The constitution of organizational legitimacy: A narrative perspective. Organization Studies, 28(8), 1149-1167. https://doi.org/10.1177/0170840607075671

Hamlet, J. D. (2011). Word! The African American oral tradition and its rhetorical impact on American popular culture. Black History Bulletin, 74(1), 27-31.

Heath, R. L. (2003). Telling a story: A narrative approach to communication during crisis. In D. P. Millar \& R. L. Heath (Eds.), Responding to crisis: A rhetorical approach to crisis communication (pp. 167-187). Routledge. https://doi. org/10.4324/9781410609496 
Heath, R. L., \& Millar, D. P. (2003). A rhetorical approach to crisis communication: Management, communication processes, and strategic responses. In D. P. Miller \& R. L. Heath (Eds.), Responding to crisis: A rhetorical approach to crisis communication. Lawrence Erlbaum Associates, Inc. https://doi. org/10.4324/9781410609496

Ingle, K., Rutledge, S., \& Bishop, J. (2011). Context matters: Principals' sensemaking of teacher hiring and on-the-job performance. Journal of Educational Administration, 49(5), 579610. https://doi.org/10.1108/09578231111159557

Kim, J., Kim, H. J., \& Cameron, G. T. (2009). Making nice may not matter: The interplay of crisis type, response type and crisis issue on perceived organizational responsibility. Public Relations Review, 35(1), 86-88. https://doi.org/10.1016/j. pubrev.2008.09.013

Lassen, I. (2006). Is the press release a genre? A study of form and content. Discourse Studies, 8(4), 503-530. https://doi. org/10.1177/1461445606061875

Lee, H., \& Jahng, M. R. (2020). The role of storytelling in crisis communication: A test of crisis severity, crisis responsibility, and organizational trust. Journalism \& Mass Communication Quarterly, 97(4), 981-1002. https://doi. org/10.1177/1077699020923607

Liberman, N., \& Trope, Y. (1998). The role of feasibility and desirability considerations in near and distant future decisions: A test of temporal construal theory. Journal of Personality and Social Psychology, 75, 5-18. https://doi.org/10.1037/00223514.75.1.5

Liu, B. F., Fowler, B. M., Roberts, H. A., \& Herovic, E. (2018). Keeping hospitals operating during disasters through crisis communication preparedness. Public Relations Review, 44(4), 585-597. https://doi.org/10.1016/j.pubrev.2018.06.002

Malecki, K., Keating, J. A., \& Safdar, N. (2020). Crisis communication and public perception of COVID-19 risk in the era of social media. Clinical Infectious Diseases, ciaa758. https://doi. org/10.1093/cid/ciaa758 
Marx, M. A., Gurley, E., Nuzzo, J., Sauer, L, Limaye, R. J., Moss, W., Lessler, J., \& Sharfstein, J. (2020, April 2). Recommendations for a metropolitain COVID-19 response. Johns Hopkins Bloomberg School of Public Health. https://www.jhsph.edu/covid-19/ articles/covid-19-recommendations-for-a-metropolitanresponse.html

Masuda, J. R., \& Garvin, T. (2006). Place, culture, and the social amplification of risk. Risk Analysis: An International Journal, 26, 437-454. https://doi.org/10.1111/j.1539-6924.2006.00749.X

Methodist Health System. (2020a, February 19). Methodist Mansfield Medical Center grant offers health science and agriculture students advanced anatomy. [Press Release]. https:// web.archive.org/web/20210412161859/https://www.meth odisthealthsystem.org/news-center/2020/february/

Methodist Health System. (202ob, May 7). Remdesivir offers hope for hospitalized COVID-19 patients. Anti-viral drug and convalescent plasma administered to Methodist patients. [Press Release]. https://web.archive.org/web/20210116075527/ https://www.methodisthealthsystem.org/news-center/2020/ may/remdesivir-offers-hope-for-hospitalized-covid-19/

Methodist Health System. (2020c, May 18). Health systems collaborate to increase COVID-19 testing, education for southern Dallas communities. [Press Release]. https://web.archive.org/ web/20200808234559/https://www.methodisthealthsystem. $\mathrm{org} /$ news-center $/ 2020 / \mathrm{may} /$ health-systems-collaborate-toincrease-covid-19-/

Methodist Health System. (2020d, June 4). Methodist Charlton Medical Center builds new emergency department. [Press Release]. https://web.archive.org/web/20200706154813/https:// www.methodisthealthsystem.org/news-center/2020/june/ methodist-charlton-medical-center-builds-new-eme/

Minchin, E. (1995). The poet appeals to his Muse: Homeric invocations in the context of epic performance. The Classical Journal, 91, 25-33. https://doi.org/10.1017/ann.2018.8

Minton, W. W. (1960, January). Homer's invocations of the Muses: Traditional patterns. In Transactions and Proceedings of the American Philological Association (Vol. 91, pp. 292-309). Johns Hopkins University Press, American Philological Association. 
Moors, M. R. (2019). What is Flint? Place, storytelling, and social media narrative reclamation during the Flint water crisis. Information, Communication \& Society, 22, 808-822. https:// doi.org/10.1080/1369118X.2019.1577477

Office of Rural Health Policy. (2002, April). Rural communities and emergency preparedness. https://web.archive. org/web/20170430222254/https://www.ruralhealthinfo. org/assets/198-319/rural-communities-and-emergencypreparedness.pdf

Olaniran, B. A., \& Williams, D. E. (2001). Anticipatory model of crisis management: A vigilant response to technological crises. In R. L. Heath (Ed.), Handbook of Public Relations, (pp. 487500). Sage. http://dx.doi.org/10.4135/9781452220727.n41

Patriotta, G. (2003). Sensemaking on the shop floor: Narratives of knowledge in organizations. Journal of Management Studies, 40, 349-375. https://doi.org/10.1111/1467-6486.00343

Peterson, J. C. (2010). CBPR in Indian country: Tensions and implications for health communication. Health Communication, 25, 50-6o. https://doi.org/10.1080/10410230903473524

Sandberg, J., \& Tsoukas, H. (2015). Making sense of the sensemaking perspective: Its constituents, limitations, and opportunities for further development. Journal of Organizational Behavior, 36, S6-S32. https://doi.org/10.1002/job.1937

Spence, A., Poortinga, W., \& Pidgeon, N. (2012). The psychological distance of climate change. Risk Analysis, 32, 957-972. https:// doi.org/10.3389/fpsyg.2020.568899

Tisch, D., \& Galbreath, J. (2018). Building organizational resilience through sensemaking: The case of climate change and extreme weather events. Business Strategy and the Environment, 27, 1197-1208. https://doi.org/10.1002/bse.2062

Topchik, M., Gross, K., Pinette, M., Brown, T., Balfour, B., \& Kein, $\mathrm{H}$. (2020, February). The rural health safety net under pressure rural hospital vulnerability. The Chartis Center for Rural Health. https://web.archive.org/web/20200303151446/https:// www.ivantageindex.com/wp-content/uploads/2020/02/ CCRH_Vulnerability-Research_FiNAL-02.14.20.pdf 
U.S. Census Bureau. (2018a). Quick Facts: Comanche County, Texas. U.S. Census Bureau. https://web.archive.org/ web/20210412162814/https://www.census.gov/quickfacts/ fact/table/comanchecountytexas/INC110219

U.S. Census Bureau. (2018b). Quick Facts: Dallas City, Texas; Fort Worth City, Texas. U.S. Census Bureau. https://web.archive.org/ web/20210412162833/https://www.census.gov/quickfacts/ fact/table/dallascitytexas,fortworthcitytexas/PSTo45219

Vick, D. (2019). Comparison of disaster preparedness between urban and rural community hospitals in New York State. Disaster Medicine and Public Health Preparedness, 13, 424-428. https://doi.org/10.1017/dmp.2018.85

Walters, E. (2020, March 24). Rural Texas hospitals should be staffing up to face coronavirus. Many can't afford to. The Texas Tribune. https://web.archive.org/web/20200325003453/ https://www.texastribune.org/2020/03/24/texas-rural-hospitals-out-money-coronavirus-threat-looms/

Weick, K. E. (1995). Sensemaking in organizations (Vol. 3). Sage. https://doi.org/10.1016/So956-5221(97)86666-3

Weinberg, T. (2020, March 17). As the coronavirus moves across boundaries, some look to Abbott for uniform restrictions. Fort Worth Star-Telegram. https:/www.star-telegram.com/news/ politics-government/article241263781.html

Yang, S. U., Kang, M., \& Johnson, P. (2010). Effects of narratives, openness to dialogic communication, and credibility on engagement in crisis communication through organizational blogs. Communication Research, 37, 473-497. https://doi. org/10.1177/0093650210362682 